\section{Activation of the Oxidative Burst in Human Monocytes Is Associated with Inhibition of Methionine- dependent Methylation of Neutral Lipids and Phospholipids}

\author{
E. Bonvini, P. Bougnoux, H. C. Stevenson, P. Miller, \\ and $\mathrm{T}$. Hoffman \\ Biological Therapeutics Branch, Biological Response Modifiers \\ Program, National Cancer Institute, Frederick Cancer Research \\ Facility, Frederick, Maryland 21701; Division of Biochemistry \\ and Biophysics, National Center for Drugs and Biologics, \\ Bethesda, Maryland 20205
}

bstract. Chemotaxis and generation of the oxidative burst by phagocytes are among the biological functions thought to require methylation reaction(s) for their expression. The present study investigated the effect of different stimuli of the oxidative burst on lipid methylation by human elutriated monocytes as measured by methyl group incorporation from [methyl- $\left.{ }^{3} \mathrm{H}\right]$ methionine into both phospholipid and neutral lipid extracts. Normal monocytes, incubated at $37^{\circ} \mathrm{C}$ for $1 \mathrm{~h}$ with $2 \mu \mathrm{M}$ methionine, incorporated $10.2-\mathrm{fmol} / 10^{6}$ cells and $73.6-\mathrm{fmol} /$ $10^{6}$ cells of methyl groups into neutral lipids and phospholipids, respectively. Stimulators of the respiratory burst, such as the chemotactic peptide $N$-formyl-L-methionyl-L-leucyl-L-phenylalanine, the tumor promoter, 12-O-tetradecanoyl phorbol-13-acetate, and the calcium ionophore, A23187, decreased the incorporation of methyl groups into both neutral lipids and phospholipids in a similar manner. Increasing the concentration of methionine in the medium reversed or attenuated the inhibition achieved at lower levels. An inverse relationship existed between the degree of methylation and the extent of stimulation of the oxidative burst, measured as superoxide anion $\left(\mathrm{O}_{2}^{-}\right)$release. Stimulated monocytes oxidized methionine to methionine sulfoxide (which cannot act as a methyl-donor), and this was dependent on activation of the respiratory burst. Elimination of the ac-

Received for publication 20 May 1983 and in revised form 27 January 1984.

J. Clin. Invest.

(c) The American Society for Clinical Investigation, Inc. 0021-9738/84/06/1629/09 \$1.00

Volume 73, June 1984, 1629-1637 cumulated methionine sulfoxide by replacement of the medium or by prevention of extracellular methionine oxidation by catalase did not effectively restore the normal level of methylation in stimulated cells, and the reduced methylation was not primarily related to a defective methionine uptake by stimulated monocytes. These data suggest that intracellular events related to activation of the respiratory burst are responsible for the decreased lipid methylation in stimulated cells, possibly by their leading to intracellular formation of methionine sulfoxide and by their limiting the availability of methyl-donor. This mechanism may be of potential relevance for the expression of biological functions where methionine-dependent reactions are involved.

\section{Introduction}

Transmethylation reactions have been implicated in a variety of biological functions in different cell types $(1,2)$. In phagocytic cells, cellular methylations are thought to be required for the generation of the oxidative burst of guinea pig macrophages (3, 4 ), for the phagocytosis by mouse macrophages (5), as well as for the chemotactic response of human leukocytes (6-8), guinea pig macrophages (7), or a mouse macrophage cell line (9). Recently, methylation reactions have been implicated in regulating the functional state of the receptor for chemotactic factor (4) and in the binding of activated mouse macrophages to tumor cells (10).

Attempts to clarify which methylation reactions were specifically involved consequent to chemoattractant exposure have led to conflicting results. By analogy with observations in bacteria (11-13), protein carboxymethylation was found to be enhanced in rabbit leukocytes exposed to chemoattractants (14), but this result was not confirmed in guinea pig macrophages (15). Attention has focused in recent years on phospholipid 
methylation (16), which was decreased when cells were treated with chemoattractants $(15,17)$. With regard to the respiratory burst, there is no current information available concerning which transmethylation reactions are involved.

We previously identified ubiquinone- 50 as the major methylated neutral lipid in human monocytes (18). We observed that activation of the respiratory burst was associated with a reduction in the rate of neutral lipid methylation. In the present study we investigated the changes induced by a chemoattractant and by other activators of the respiratory burst on the incorporation by human monocytes of the methyl group from methionine into neutral lipids, as well as into phospholipids, two metabolic pathways whose biological significance is likely to be different. Our intent was to discriminate between unique involvement of neutral lipid methylation or generalized effects on other metabolic pathways. An inverse relationship was observed between activation of the oxidative burst and the extent of incorporation of methyl groups into cellular lipids. Methylation of both neutral lipids and phospholipids was affected in a similar manner, suggesting that there is a common mechanism underlying this phenomenon.

\section{Methods}

Reagents. The chemotactic peptide, $N$-formyl-L-methionyl-L-leucyl-Lphenylalanine (FMLP)' (Sigma Chemical Co., St. Louis, MO), and the calcium ionophore, A23187 (Boehringer-Mannheim Biochemicals, Indianapolis, IN), were dissolved in dimethylsulfoxide (Sigma Chemical Co.) and stored frozen $\left(-70^{\circ} \mathrm{C}\right)$ in aliquots. 12-O-tetradecanoyl phorbol13-acetate (TPA) was purchased from CCR, Inc. (Eden Prairie. MN), dissolved in acetone, and stored at $-30^{\circ} \mathrm{C}$. L-methionine, L-methionineDL-sulfoxide, L-methionine sulfone, cytochrome $c$ (from horse heart, type III), catalase (EC 1.11.1.6, from bovine liver, 11,800 Sigma U/mg protein ${ }^{2}$ ), superoxide dismutase (SOD, EC 1.15.1.1, from bovine blood, type I), and essentially fatty acid-free bovine serum albumin were from Sigma Chemical Co. S-adenosyl-methionine was from BoehringerMannheim Biochemicals. RPMI 1640 medium (methionine-free where indicated), Earle's balanced salt solution (EBSS), and Hepes buffer, $\mathrm{pH}$ 7.4, were from Gibco Laboratories (Grand Island, NY). Heat-inactivated fetal bovine serum was from Biofluids, Inc. (Rockville, MD). L-[methyl$\left.{ }^{3} \mathrm{H}\right]$ methionine $(12-80 \mathrm{Ci} / \mathrm{mmol})$ and $\mathrm{L}-\left[{ }^{35} \mathrm{~S}\right]$ methionine $(955-1197.5$ $\mathrm{Ci} / \mathrm{mmol}$ ) were obtained from New England Nuclear (Boston, MA). L[methyl- ${ }^{3} \mathrm{H}$ ]methionine sulfoxide was prepared by oxidation of $\mathrm{L}$-[methyl${ }^{3} \mathrm{H}$ ]methionine by the method reported by Tsan (19). Analytical grade organic solvents were from J. T. Baker Chemical Co. (Phillipsburg, NJ).

Cells. Monocytes were purified by a modification of an elutriation procedure detailed previously (20). Cell purity, assessed by Wright's staining, nonspecific esterase (21), and latex phagocytosis was $>93 \%$.

1. Abbreviations used in this paper: EBSS, Earle's balanced salt solution; FMLP, $N$-formyl-L-methionyl-L-leucyl-L-phenylalanine; SOD, superoxide dismutase: TPA, 12-O-tetradecanoyl phorbol-13-acetate; TLC, thin-layer chromatography; TCA, trichloroacetic acid.

2. 1 Sigma unit will decompose $1.0 \mu \mathrm{mol}$ of $\mathrm{H}_{2} \mathrm{O}_{2}$ per minute at $\mathrm{pH}$ 7.0 at $25^{\circ} \mathrm{C}$, while the $\mathrm{H}_{2} \mathrm{O}_{2}$ concentration falls from 10.3 to $9.2 \mu \mathrm{mol} /$ $\mathrm{ml}$ of reaction mixture.
In each experiment, cell viability, assessed by trypan blue exclusion, was $>95 \%$.

Evaluation of neutral lipid and phospholipid methyl group incorporation. The methylation of neutral lipids was assayed by measuring the incorporation by intact cells of the $\left[{ }^{3} \mathrm{H}\right]$ methyl group from [methyl${ }^{3} \mathrm{H}$ ]methionine into nonpolar lipids extracted with heptane (18). Monocytes $\left(3-4 \times 10^{6} / \mathrm{ml}\right)$, with or without stimulating agents, were incubated in polypropylene tubes (Falcon 2059, Falcon Labware, Oxnard, CA) at $37^{\circ} \mathrm{C}$ in a $5 \% \mathrm{CO}_{2}$-air humidified atmosphere in $0.5 \mathrm{ml}$ methioninefree RPMI 1640 medium containing $25 \mathrm{mM}$ Hepes buffer, $5 \mathrm{mg} / \mathrm{ml}$ fatty acid-free bovine serum albumin, and labeled methionine at the final concentrations specified. Each test was performed in duplicate. The reaction was stopped at the indicated time by adding $2.5 \mathrm{ml}$ of cold EBSS. After centrifugation at $400 \mathrm{~g}$, supernatants were saved for quantification of the remaining radioactivity and for analysis by thinlayer chromatography (TLC). Cells were subsequently washed twice and resuspended in $0.2 \mathrm{ml}$ of EBSS, followed by addition of $2 \mathrm{ml}$ of methanol and by vigorous vortexing. Nonpolar lipids were extracted with $5 \mathrm{ml}$ of heptane and were followed by a second extraction with 3 $\mathrm{ml}$ of heptane. An aliquot of the pooled heptane extract was transferred to scintillation vials and evaporated. Radioactivity was quantified by liquid scintillation counting, using $10 \mathrm{ml}$ Aquassure (New England Nuclear) as scintillation fluid. Efficiency was evaluated for each sample using the sample channel ratio, and disintegrations per minute were converted into femtomoles of methyl groups from the specific activity after correction for isotopic dilution.

Phospholipids were subsequently extracted from the lower methanol/ water phase by adding $1.4 \mathrm{ml}$ of water, $2 \mathrm{ml}$ of methanol, and $2 \mathrm{ml}$ of chloroform followed by vigorous shaking. Partition into two phases occurred upon addition of $2 \mathrm{ml}$ of chloroform and $2 \mathrm{ml}$ of water, as specified by Bligh and Dyer (22). After centrifugation, the lower organic phase was filtered through cotton wool and radioactivity was quantified as above. Characterization of the labeled products in both heptane and chloroform extracts of monocytes has been previously reported (18).

Chemotaxis assay. Chemotaxis was measured in blind-well chemotactic chambers (Nucleopore Corp., Pleasanton, CA) using a modification of the method of Snyderman et al. (23). The upper well of the chamber, containing $200 \mu \mathrm{l}$ of cell suspension $\left(2 \times 10^{6}\right.$ cells $/ \mathrm{ml}$ in RPMI $1640,10 \%$ fatty acid-free bovine serum albumin), was separated from the lower well by a 5.0- $\mu \mathrm{m}$ pore size nitrocellulose filter (Millipore Corp., Milford, MA). Medium with or without FMLP at the indicated concentrations was placed in the lower compartment. Each assay was performed in duplicate. After $2 \mathrm{~h}$ at $37^{\circ} \mathrm{C}$ in a humidified incubator, the filters were removed, fixed, stained with haematoxylin (Fisher Scientific Co., Indiana, PA), dehydrated, cleared, dried, and mounted in synthetic resin (Permount, Fisher). The migratory response was measured according to the "leading front" technique of Zigmond and Hirsch (24), by examination at $\times 400$ magnification of five randomly chosen fields for each filter, using a microscope (Carl Zeiss, Federal Republic of Germany) equipped with a microngraduated micrometric wire.

Assay of superoxide production. Superoxide production was measured by SOD-inhibitable reduction of ferricytochrome $c$ using the modified microtechnique of Pick and Mizel (25). Briefly, $2 \times 10^{5}$ cells/well were dispensed into flat-bottomed, 96-well microtiter tissue culture plates (Falcon 3072, Falcon Labware, MicroTest III) in $100 \mu$ l EBSS without phenol red, containing $160 \mu \mathrm{M}$ cytochrome $c$ and the appropriate stimulus, when indicated. Four replicate wells were employed for each determination. The plates were incubated for $1 \mathrm{~h}$ at $37^{\circ} \mathrm{C}$ and read in a micro-ELISA ${ }^{\oplus}$ autoreader (Dynatech Inc., McLean, VA) at $550 \mathrm{~nm}$. 
Wells to which $300 \mathrm{U} / \mathrm{ml}$ SOD were added served as blanks. Results were expressed in $\mathrm{nmol} \mathrm{O}_{2}^{-} / 10^{6}$ cells/h using an extinction coefficient of $21 \times 10^{3} \mathrm{M}^{-1} \mathrm{~cm}^{-1}$, which was corrected for the calculated length of the light path.

Separation of methionine and methionine sulfoxide by $T L C$. The presence of methionine and methionine sulfoxide in the supernatants of monocytes incubated with labeled methionine was detected as follows. 10-20 $\mu$ l of supernatant were diluted 1:1 with ethanol and applied under nitrogen to a $250-\mu \mathrm{m}$ thickness, silica gel $\mathrm{G}$ plate with fluorescent indicator and preadsorbent spotting area (LK6F, Whatman Chemical Separation, Inc., Clifton, NJ). Plates were developed with either $t$-butanol/methylethyl-ketone/water/ammonium hydroxide $(40: 30: 20: 10)$ or $N$-butanol/ acetic acid/water (50:25:25) (19). The location of standards was visualized under a short-wave ultraviolet lamp after exposure of the plate to iodine vapors. Both systems allowed separation of internal standards, including s-adenosyl-methionine, methionine sulfoxide, methionine sulfone, and methionine. The latter system was subsequently used for routine determination. The percentage distribution of radioactivity was quantified by scanning with a TLC plate scanner $(18,26)$ (imaging proportional counter, Bioscan Inc., Washington, DC).

Statistical analysis. Significance was determined from the $t$ test for paired data.

\section{Results}

Effect of the chemotactic peptide, FMLP, and other stimulators of the respiratory burst on the level of methyl group incorporation into neutral lipids and phospholipids of human monocytes. Human monocytes incubated for $1 \mathrm{~h}$ at $37^{\circ} \mathrm{C}$ in the presence of
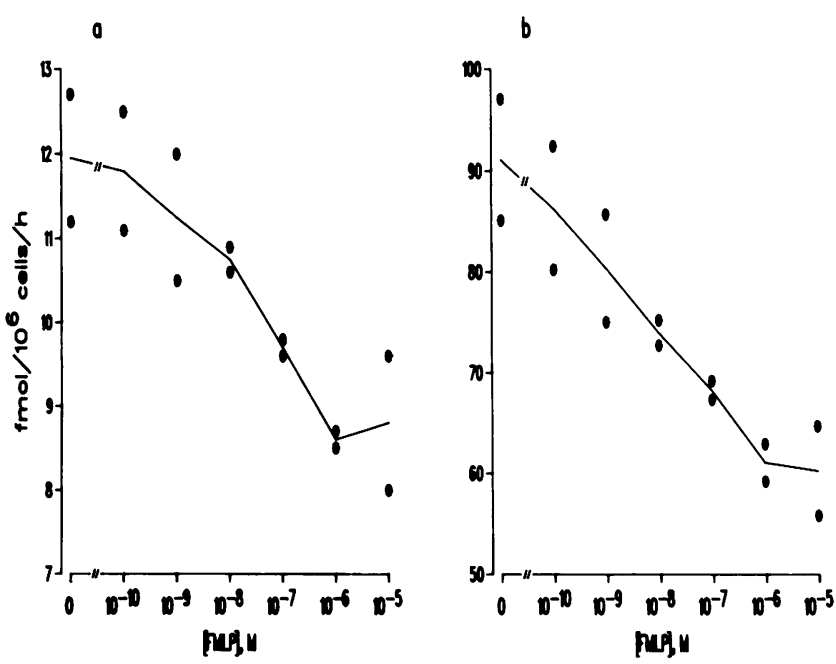

Figure 1. Dose-response curve for the effect of FMLP on methyl group incorporation into neutral lipid $(a)$ and phospholipid $(b)$ extracts of human monocytes. $2 \times 10^{6}$ cells were resuspended in medium containing $2 \mu \mathrm{M}$ [methyl ${ }^{3} \mathrm{H}$ ] methionine in the presence of the indicated concentration of the chemoattractant. After $1 \mathrm{~h}$ of incubation at $37^{\circ} \mathrm{C}$, cells were washed and subsequently extracted as described in Methods. Curves represent the means of experimental values (๑) from two separate experiments. In each experiment, differences between duplicates were $<5 \%$ of the mean.
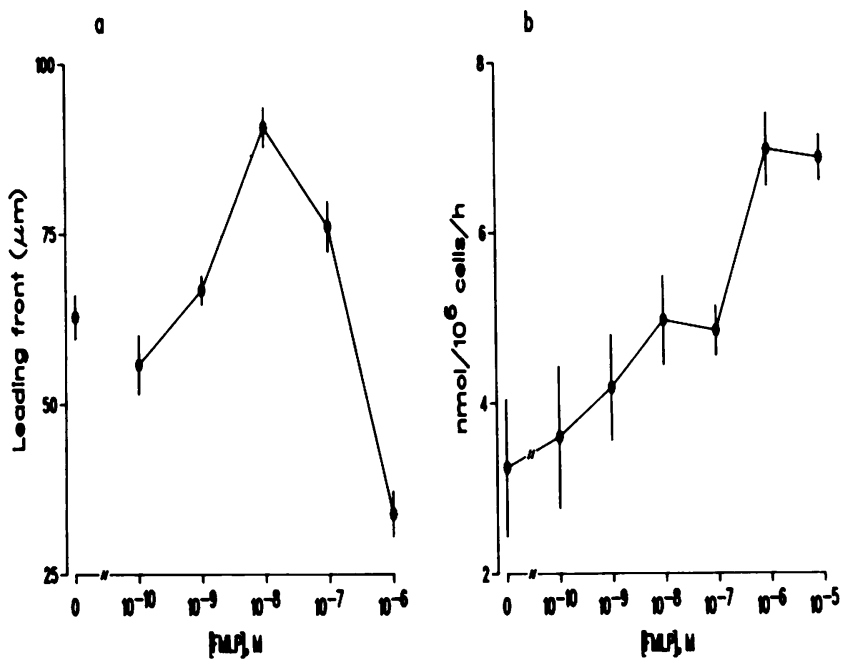

Figure 2. (a) Effect of FMLP on human monocyte locomotion. Random (unstimulated) motility and chemotaxis toward FMLP were evaluated as described in Methods and expressed as the distance $(\mu \mathrm{m})$ traveled by the cellular-leading front. The experiment shown represents three performed. The migratory response at each dose is expressed as the mean \pm SEM of the 10 fields read. (b) Dose-response curve for the effect of FMLP on $\mathrm{O}_{2}^{-}$-release by human monocytes. The assay was carried out as described in Methods using FMLP at the indicated concentration as a stimulus. Each point represents the mean \pm SEM of three separate experiments.

$2 \mu \mathrm{M}$ [methyl- $\left.{ }^{3} \mathrm{H}\right]$ methionine incorporated $10.2 \pm 2.1-\mathrm{fmol} / 10^{6}$ cells and $73.6 \pm 21.8-\mathrm{fmol} / 10^{6}$ cells of labeled methyl groups into neutral lipids and phospholipids, respectively (mean \pm SD of six experiments). The chemotactic peptide, FMLP, induced under the same experimental conditions a dose-dependent decrease in the incorporation of methyl groups into each lipid fraction (Fig. 1). The effect of FMLP was comparable in both lipid fractions, with maximal effect reached at $10^{-6} \mathrm{M}$ FMLP. The mean relative decrease observed with $10^{-6} \mathrm{M}$ FMLP was $25.1 \pm 9.6 \%(P<0.005)$ for neutral lipids and $29.7 \pm 10.4 \%$ $(P<0.005)$ for phospholipids (mean \pm SD of six experiments). Dimethylsulfoxide, the dissolving vehicle for FMLP, was without effect at the highest concentration employed $(0.02 \% \mathrm{v} / \mathrm{v})$ (not shown).

In an attempt to correlate this observation with the biological effects of FMLP, we also examined the dose-response effects of this compound on locomotion and superoxide anion $\left(\mathrm{O}_{2}^{-}\right)$release by human monocytes (Fig. 2). $10^{-8} \mathrm{M}$ was the optimal concentration of FMLP as a chemoattractant, whereas $10^{-6} \mathrm{M}$ induced maximal effects on superoxide production. $\mathrm{O}_{2}^{-}$production increased over the same concentration range of FMLP that induced a decreased methyl group incorporation into cellular lipids, suggesting a correlation between the two phenomena. Therefore, we evaluated the effect of nonchemotactic stimuli of the respiratory burst. Fig. 3 shows the dose-titration of $\mathrm{O}_{2}^{-}$release by human monocytes in response to TPA or to the 


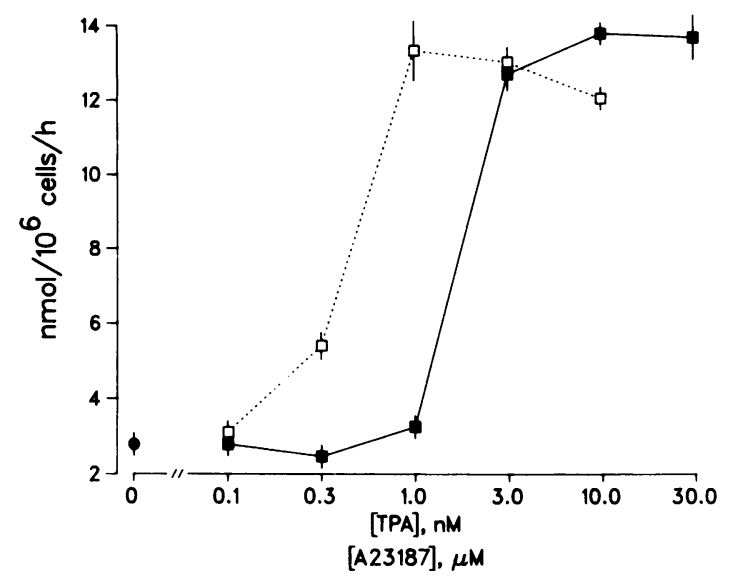

Figure 3. Dose-response effects of TPA or the calcium ionophore, A23187, on $\mathrm{O}_{2}^{-}$-release by human monocytes. The data shown for medium alone (๑), TPA ( $\bullet$ ), or A23187 ( $\square$ ) are the means \pm the experimental errors of an experiment performed in quadruplicate. Each experimental error was calculated as the sum of the SEM values for the replicate blanks and for the replicates of each data-point.

calcium ionophore, A23187. Based on this titration, a single dose of each compound that resulted in an equivalent production of $\mathrm{O}_{2}^{-}$was tested for its effect on lipid methylation (Table I). The decreased methyl group incorporation into each lipid fraction was similar with both agents. Furthermore, evaluation of the dose-response of the TPA effect on methyl group incorporation into lipids showed $10 \mathrm{nM}$ to be the concentration giving the maximal effect, as was observed for $\mathrm{O}_{2}^{-}$release (Fig. 4). Lymphocytes, which exhibited a similar pattern of distribution of methyl groups incorporated into neutral lipids and phospholipids as monocytes, did not release detectable amounts of $\mathrm{O}_{2}^{-}$in response to TPA and displayed no reduction in the

Table I. Effect of Stimulators of the Respiratory Burst on Methyl Group Incorporation into Lipids by Human Monocytes

\begin{tabular}{lcc}
\hline & \multicolumn{2}{c}{ Methyl group incorporation* into: } \\
\cline { 2 - 3 } Treatment & Neutral lipids & Phospholipids \\
\hline & $\%$ & $\%$ \\
Medium & 100.0 & 100.0 \\
FMLP $\left(10^{-6} \mathrm{M}\right)$ & 87.8 & 84.3 \\
TPA $(10 \mathrm{nM})$ & 15.6 & 22.7 \\
A23187 $(3 \mu \mathrm{M})$ & 14.6 & 21.5 \\
\hline
\end{tabular}

* Methyl group incorporation was evaluated over a $1-\mathrm{h}$ period in the presence of $2 \mu \mathrm{M}$ [methyl- ${ }^{3} \mathrm{H}$ ]methionine as described in Methods. The results are expressed as percentage of the control value from an experiment performed in duplicate. The incorporation in mediumtreated cells was $11.1 \mathrm{fmol} / 10^{6}$ cells for neutral lipids and $83.0 \mathrm{fmol} /$ $10^{6}$ cells for phospholipids. Differences between replicates never exceeded $5 \%$ of the mean.

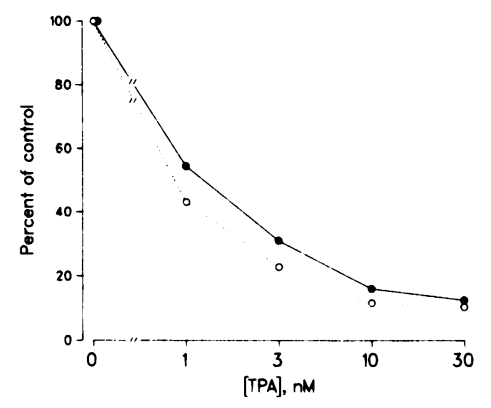

Figure 4. Dose-response curve for the effect of TPA on the extent of methyl group incorporation into neutral lipids $(\bullet)$ and phospholipids $(0)$ by human monocytes. The experiment was performed as described in Methods over a 3-h incubation period in the presence of $15 \mu \mathrm{M}$ [methyl${ }^{3} \mathrm{H}$ ]methionine. The data

are expressed as percentage of control (medium-treated cells). Incorporation in the absence of TPA was $129 \mathrm{fmol} / 10^{6}$ cells for neutral lipids and $832.2 \mathrm{fmol} / 10^{6}$ cells for phospholipids. Differences between duplicates did not exceed $5 \%$ of the mean value.

amount of methyl groups incorporated into either lipid fraction in response to up to $100 \mathrm{nM}$ TPA (data not shown).

The decrease in the incorporation of methyl groups into both neutral lipids and phospholipids followed the same time course (Fig. 5). This was the case for either FMLP- or TPAtreated cells. The effect of FMLP approached its maximum after $1 \mathrm{~h}$ of incubation, while the effect of TPA was maximal after $2 \mathrm{~h}$.

These data suggest that these two different types of methylation reactions are affected by a common mechanism which is related to events occurring during the stimulation of the oxidative burst.

Effect of different concentrations of methionine on the FMLPor TPA-induced decrease of methyl group incorporation into
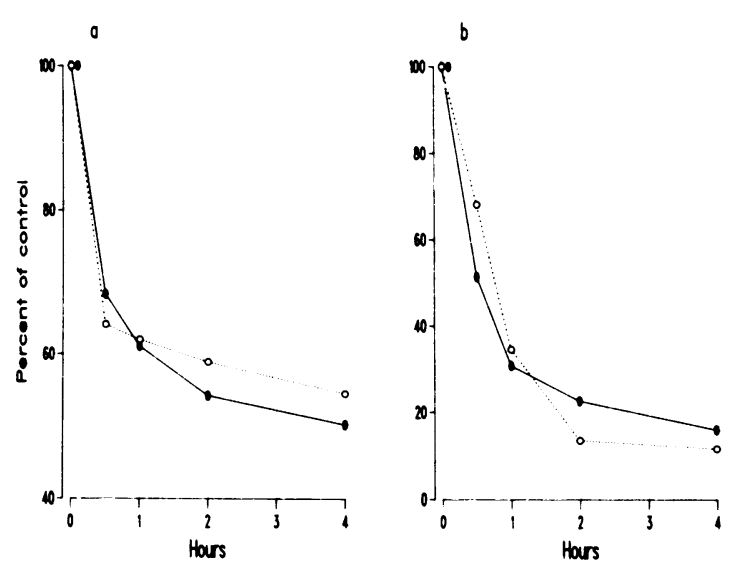

Figure 5. Time course for the effect of FMLP $10^{-6} \mathrm{M}(a)$, and TPA $10 \mathrm{nM}(b)$, on the level of methyl group incorporation into monocyte neutral lipids $(\bullet)$ and phospholipids $(0)$. Treated or untreated monocytes were incubated in medium containing $2 \mu \mathrm{M}$ (FMLP) or $15 \mu \mathrm{M}$ (TPA) [methyl- ${ }^{3} \mathrm{H}$ ]methionine and, at the indicated time, cells were washed and lipids extracted as described in Methods. The data are expressed as percentage of the control (medium-treated cells) level of methyl group incorporation. 
monocyte lipids. The relative effect of FMLP and TPA on lipid methylation by human monocytes was dependent upon the concentration of methionine in the incubation medium (Fig. 5 ). When the methionine concentration was increased from 2 to $20 \mu \mathrm{M}$, there was little or no inhibition of methyl group incorporation into either lipid fraction in FMLP-treated monocytes. Conversely, more inhibition was seen when the methionine concentration was lowered to $0.2 \mu \mathrm{M}$ (Fig. $6 a$ ). The effect of TPA, which had a more marked action than FMLP when tested at the lowest concentration of methionine $(2 \mu \mathrm{M})$, was attenuated by increasing methionine up to $100 \mu \mathrm{M}$, the highest concentration tested (Fig. $6 \mathrm{~b}$ ). This shows that these agents did not induce an inhibition of lipid methylation by a toxic, nonspecific, effect and suggests that the mechanism involved is related to the availability of methyl donors.

Oxidation of methionine by stimulated monocytes. Since the degree of reduction in methyl group incorporation into monocyte lipids was found to be dependent on the concentration of methionine and to be associated with activation of the respiratory burst, we investigated whether oxidation of methionine by stimulated monocytes occurred in our system. When monocytes were incutated in medium containing [methyl- ${ }^{3} \mathrm{H}$ ]labeled methionine, in the presence or absence of either FMLP $\left(10^{-6} \mathrm{M}\right)$ or TPA $(10 \mathrm{nM})$, no difference in the amount of radioactivity recovered in the supernatants of control or stimulated monocytes was observed (data not shown). However, analysis by TLC of supernatants from stimulated monocytes showed that the percentage of radioactivity co-migrating with the methionine sulfoxide internal standard was increased, while radioactivity co-
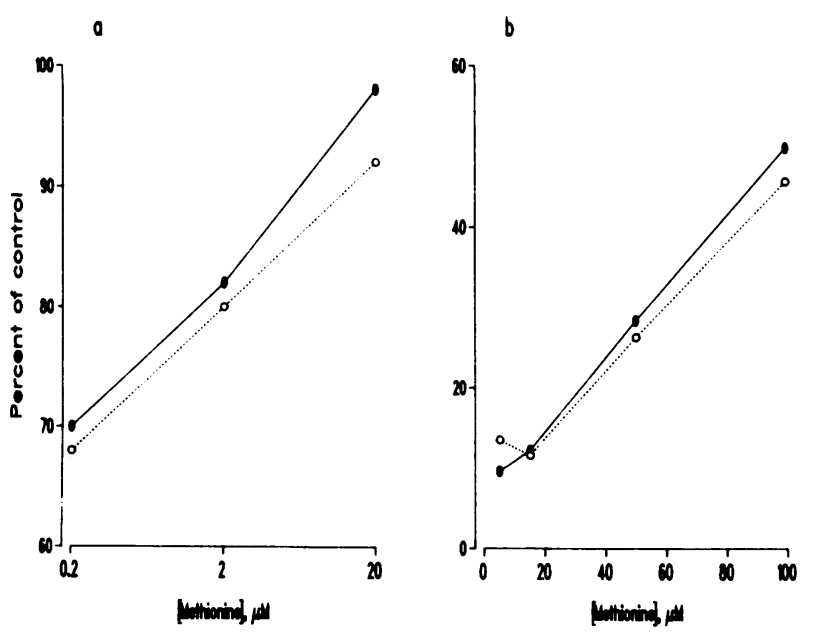

Figure 6. Effect of different concentrations of methionine on the FMLP $(a)$ - or TPA $(b)$-induced decrease in methyl group incorporation into monocyte neutral lipids (•) and phospholipids (O). Experiments were performed as described in Methods over a 1-h period with $10^{-6}$ M FMLP or over a 3-h period with $10 \mathrm{nM}$ TPA. Results are expressed as percentage of control (medium-treated cells). Differences between duplicates did not exceed $5 \%$ of the mean value.
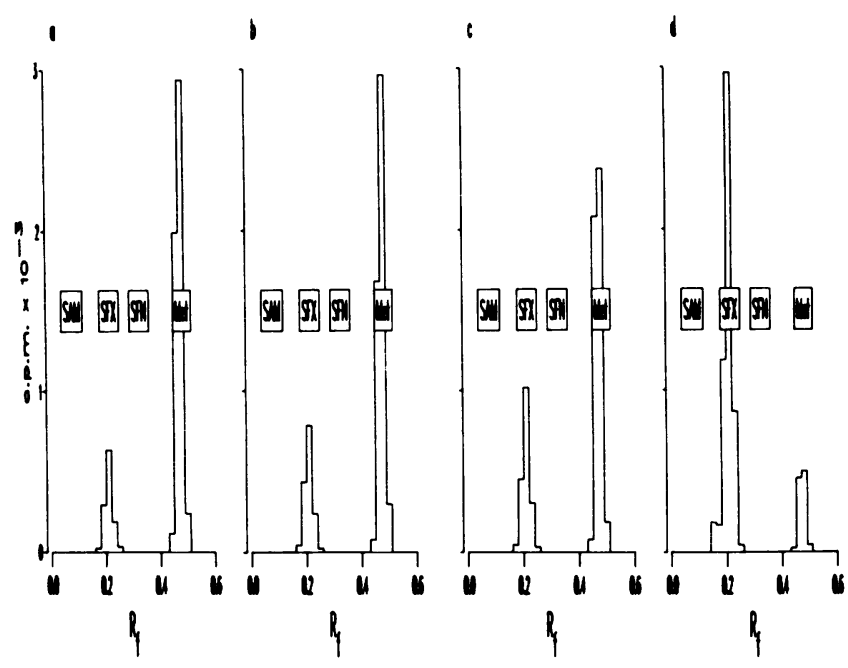

Figure 7. Chromatographic pattern of the radioactivity from labeled methionine in supernatants of nonstimulated and stimulated monocytes. Supernatants containing $2 \mu \mathrm{M}$ [methyl- ${ }^{3} \mathrm{H}$ ]methionine were harvested after $1 \mathrm{~h}$ of incubation at $37^{\circ} \mathrm{C}$ and separated by TLC (as described in Methods) with $N$-butanol/acetic acid/water (50:25:25) as the solvent system. A control TLC of the incubation medium at time zero was also performed $(a)$. The other chromatograms refer to medium-treated monocytes $(b)$, FMLP $\left(10^{-6} \mathrm{M}\right)$-treated monocytes $(c)$, and TPA $(10 \mathrm{nM})$-treated monocytes $(d)$. Labels represent location of the internal standards. SAM, $S$-adenosyl-methionine; Met, methionine; SFN, methionine sulfone; SFX, methionine sulfoxide.

migrating with the methionine internal standard was decreased (Fig. 7). No other labeled compounds were detected. Spontaneous oxidation of methionine was not observed when monocytes were omitted from the incubation (data not shown). These results are consistent with a previous report (27) showing that human neutrophils are capable of oxidizing methionine to methionine sulfoxide by activation of the respiratory burst.

Since methionine sulfoxide was present in the supernatant of stimulated monocytes, we compared its incorporation into cells to that of (unoxidized) methionine using the corresponding radiolabeled isotopes. The total cell-associated radioactivity of monocytes incubated with [methyl $-{ }^{3} \mathrm{H}$ ]methionine sulfoxide was $8.2 \%$ of the amount found in cells incubated with an identical concentration of [methyl- ${ }^{3} \mathrm{H}$ ]methionine (Table II). This reduction was principally accounted for by a decrease in the radioactivity incorporated into the TCA-precipitable pool; a less evident decrease was observed in the TCA-soluble radioactivity. The addition of FMLP or TPA resulted in minimal changes in this pattern. Under similar conditions, incorporation of (unoxidized) methionine was reduced $15.4 \%$ by FMLP treatment and $62.7 \%$ by TPA treatment, due almost entirely to reduction in the TCA-precipitable counts.

Since the amount of radioactivity from methionine sulfoxide recovered in the TCA-soluble material was considerable $\mathbf{6 3 . 5 \%}$ of the radioactivity recovered from cells incubated with labeled 
Table II. Comparison of the Incorporation of Methionine Or Methionine Sulfoxide into Human Monocytes

\begin{tabular}{lllll}
\hline & \multicolumn{4}{l}{ Radioactivity $\left(\mathrm{dpm} \times 10^{-3}\right)$ incorporated into $10^{6}$ cells $\mathrm{s}^{*}$} \\
\cline { 2 - 5 } Isotope & Treatment & $\begin{array}{l}\text { TCA-soluble } \\
\text { material }\end{array}$ & $\begin{array}{l}\text { TCA-precipitable } \\
\text { material }\end{array}$ & Total \\
\hline [Methyl- $\left.{ }^{-} \mathrm{H}\right]$ & Medium & 73.4 & 550.8 & 624.2 \\
Methionine & FMLP $\left(10^{-6} \mathrm{M}\right)$ & 65.6 & 462.4 & 528.0 \\
& TPA $(10 \mathrm{nM})$ & 61.5 & 171.9 & 233.4 \\
[Methyl- $\left.{ }^{3} \mathrm{H}\right]$ & Medium & 46.6 & 4.4 & 51.0 \\
Methionine & FMLP $\left(10^{-6} \mathrm{M}\right)$ & 44.9 & 3.9 & 48.8 \\
Sulfoxide & TPA $(10 \mathrm{nM})$ & 39.1 & 4.1 & 43.2 \\
\hline
\end{tabular}

* $2 \times 10^{6}$ cells were incubated for $30 \mathrm{~min}$ with either methionine or methionine sulfoxide $(2 \mu \mathrm{M}, 15 \mathrm{Ci} / \mathrm{mmol} \mathrm{sp}$ act $)$ under conditions described. At the end of the incubation, cells were washed three times with EBSS. $1 \mathrm{ml}$ of $10 \%$ cold TCA was added to the cell pellet together with $10 \mu \mathrm{l}$ of $20 \%$ BSA as carrier. The mixture was incubated at $4^{\circ} \mathrm{C}$ overnight before centrifugation at $15,000 \mathrm{rpm}$ for $15 \mathrm{~min}$. The supernatant was collected and counted. The precipitate was washed once with an additional $1 \mathrm{ml}$ cold TCA and the pellet was solubilized with $0.5 \mathrm{ml}$ of $1 \% \mathrm{SDS}$ and counted.

methionine) (Table II), we questioned whether it might represent a pool of potential methyl donors. The amount of labeled lipids extracted from cells incubated for $1 \mathrm{~h}$ at $37^{\circ} \mathrm{C}$ with [methyl${ }^{3} \mathrm{H}$ ]methionine sulfoxide $(2 \mu \mathrm{M})$ was 10.1 (neutral lipids) and $15.7 \%$ (phospholipids) of that of control cells incubated with [methyl- ${ }^{3} \mathrm{H}$ ]methionine (not shown in the table). This amount was lower than that accounted for by the reduced radioactivity in the TCA-soluble pool of cells incubated with labeled methionine sulfoxide. Together with the reduced incorporation of methionine sulfoxide in the TCA-precipitable material, the reduced amount of methyllabeled lipids extracted from cells incubated with methionine sulfoxide suggests that the oxidized analogue of methionine can not be used by monocytes, even if it is present intracellularly.

The extracellular presence of methionine sulfoxide in stimulated cultures raised the possibilities that its accumulation may exert a direct inhibitory effect, or that decreased methyl group incorporation into neutral lipid may simply reflect extracellular degradation of the methyl donor. Addition of exogenous methionine sulfoxide to cells incubated with labeled methionine failed to affect the extent of isotope incorporation into lipids (data not shown), which ruled out a direct (or toxic) effect by methionine sulfoxide. To address the latter possibility, TPAstimulated or nonstimulated monocytes were incubated at $37^{\circ} \mathrm{C}$ for $1 \mathrm{~h}$, and the medium was replaced at regular intervals with identical aliquots containing labeled methionine (Fig. 8). The results showed that replacement of the medium did not prevent the TPA-induced effect on neutral lipid and phospholipid methylation.

To further distinguish between the extracellular and intracellular events responsible for the reduced level of methyl group incorporated into lipids by stimulated cells, TPA-stimulated or unstimulated monocytes were studied in the presence or absence of the extracellular superoxide scavengers, SOD, and cytochrome $c$, and in the presence or absence of the $\mathrm{H}_{2} \mathrm{O}_{2}$ degrading enzyme, catalase (Table III). Each of the nonpenetrating agents employed had an effect in preventing methionine sulfoxide formation in the supernatant, but they failed to result in a corresponding prevention of the TPA-induced decrease in methyl group incorporation. This was particularly evident with catalase, where unimpaired availability of extracellular unoxidized methionine was accompanied by only a partial attenuation of the TPA effect. Furthermore, when incorporation of methionine was studied under conditions where methionine sulfoxide formation in the medium was prevented by catalase, TPA treatment resulted in a reduction of $38(30 \mathrm{~min})$ and $21 \%(60 \mathrm{~min})$ in the amount of cell-associated radioactivity (Table IV). Along with a decrease of 54.3 (30 $\mathrm{min}$ ) or $45.6 \%$ (60 $\mathrm{min}$ ) in TCA-precipitable radioactivity, an increase of 81.1 (30 $\mathrm{min})$ and $142.0 \%$ (60 $\mathrm{min}$ ) in TCA-soluble radioactivity was observed. This finding further supports the possibility of a reduced utilization of methionine from the intracellular, TCA-soluble, pool in the absence of impaired uptake of the amino acid.

\section{Discussion}

This study shows that the chemotactic peptide, FMLP, and other nonchemotactic stimuli of the respiratory burst decreased phospholipid and neutral lipid methylation in human monocytes to an extent that was related to their activation of the oxidative

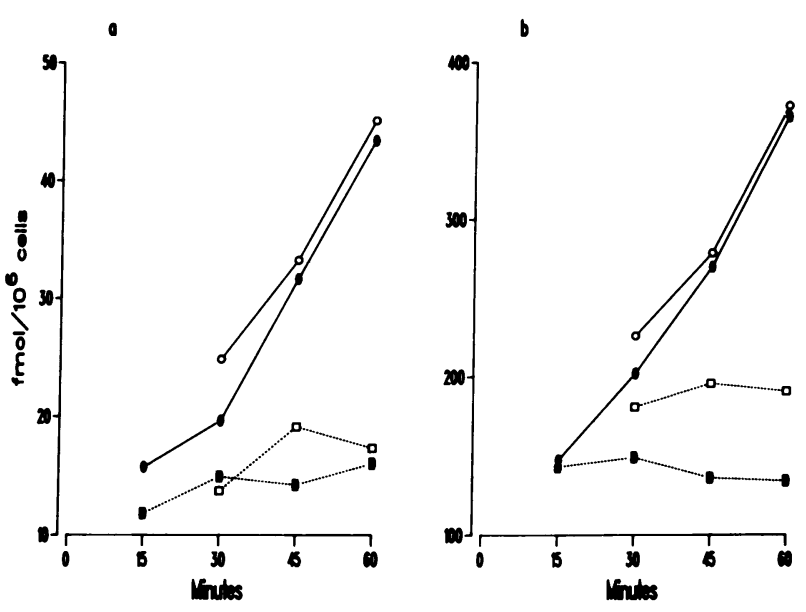

Figure 8. Effect of periodical replacement of medium containing fresh methionine on incorporation of methyl groups into neutral lipids $(a)$ and phospholipids $(b) .2 \times 10^{6}$ monocytes were incubated at $37^{\circ} \mathrm{C}$ in medium containing $15 \mu \mathrm{M}$ [methyl- ${ }^{3} \mathrm{H}$ ]methionine in the presence or absence of $10 \mathrm{nM}$ TPA. At 15-min intervals tubes were placed in the cold, centrifuged, the supernatant was removed, fresh medium containing an identical concentration of labeled methionine (with [ㅁ] or without [0] TPA, as indicated) was added, and tubes were then restored to $37^{\circ} \mathrm{C}$ to complete their incubation. Control tubes were similarly handled, without replacing medium $(\mathbf{n}, \bullet)$. Data shown are the means of two separate experiments. 
Table III. Effect of SOD, Cytochrome C, and Catalase on Methionine Oxidation and Methyl Group Incorporation into Lipids by Human Monocytes*

\begin{tabular}{|c|c|c|c|c|}
\hline \multirow[b]{2}{*}{ Treatment } & \multicolumn{2}{|c|}{ Distribution of radioactivity in the supernatant $\neq$} & \multicolumn{2}{|c|}{ Methyl group incorporation into: } \\
\hline & Methionine & Methionine sulfoxide & Neutral lipids & Phospholipids \\
\hline & $\%$ & $\%$ & $\%$ & $\%$ \\
\hline Medium & 60.2 & 36.9 & 100.0 & 100.0 \\
\hline Medium + SOD (300 U/ml) & 72.2 & 24.8 & 89.7 & 90.2 \\
\hline Medium + cytochrome $c(160 \mu \mathrm{M})$ & 79.0 & 17.0 & 87.7 & 88.2 \\
\hline Medium + catalase $(1,000 \mathrm{U} / \mathrm{ml})$ & 80.8 & 15.5 & 140.3 & 89.1 \\
\hline TPA $(10 \mathrm{nM})$ & 6.4 & 91.7 & 42.1 & 36.9 \\
\hline TPA $(10 \mathrm{nM})+\operatorname{SOD}(300 \mathrm{U} / \mathrm{ml})$ & 19.5 & 78.4 & 43.8 & 39.9 \\
\hline TPA $(10 \mathrm{nM})+$ cytochrome $c(160 \mu \mathrm{M})$ & 34.8 & 61.3 & 48.0 & 35.3 \\
\hline TPA $(10 \mathrm{nM})+$ catalase $(1,000 \mathrm{U} / \mathrm{ml})$ & 62.1 & 34.4 & 60.5 & 53.5 \\
\hline
\end{tabular}

* $2.5 \times 10^{6}$ monocytes were incubated for $3 \mathrm{~h}$ with $15 \mu \mathrm{M}$ [methyl- ${ }^{3} \mathrm{H}$ ]methionine under the conditions described in Methods and treated as indicated. Aliquots of supernatants were counted, separated by TLC, and the relative amount of methionine and methionine sulfoxide was determined. Cells were washed and extracted for quantification of methyl group incorporation into neutral lipids and phospholipids. $\ddagger$ The total amount of radioactivity in the supernatants at the end of $3 \mathrm{~h}$ of incubation was not different from that at time zero. The results represent the distribution of the radioactivity obtained by TLC analysis of the supernatants. The analysis of the incubation medium at time zero showed 83.0 and $13.9 \%$ of the radioactivity migrating as methionine and methionine sulfoxide, respectively.

burst, which was measured as $\mathrm{O}_{2}^{-}$production. This effect was reversed by increasing the concentration of methionine in the medium. Limiting the availability of methionine to the cells by extracellular oxidation to methionine sulfoxide did not entirely account for the decreased methyl group incorporation observed; rather, evidence gained by the use of nonpenetrating agents that

Table IV. Incorporation of $\left[{ }^{35} S\right]$ Methionine by Stimulated Monocytes in the Presence of Catalase

\begin{tabular}{lllll}
\hline & & \multicolumn{2}{l}{$\begin{array}{l}\text { Radioactivity }\left(\mathrm{cpm} \times 10^{-3}\right) \text { incorporated } \\
\text { into } 10^{6} \text { cells* }\end{array}$} \\
\cline { 3 - 5 } $\begin{array}{l}\text { Incubation } \\
\text { time }\end{array}$ & Treatment & $\begin{array}{l}\text { TCA- } \\
\text { soluble } \\
\text { material }\end{array}$ & $\begin{array}{l}\text { TCA- } \\
\text { precipitable } \\
\text { material }\end{array}$ & Total \\
\hline min & & & & \\
30 & Medium & 40.8 & 290.8 & 331.6 \\
& TPA (10 nM) & 73.1 & 133.0 & 206.1 \\
60 & Medium & 56.9 & 634.1 & 691.0 \\
& TPA (10 nM) & 137.9 & 408.2 & 546.1 \\
\hline
\end{tabular}

\footnotetext{
* $2 \times 10^{6}$ monocytes were incubated for 30 and 60 min with $2 \mu \mathrm{m}$ $\left[{ }^{35} \mathrm{~S}\right]$ methionine in the presence of $1,000 \mathrm{U} / \mathrm{ml}$ of catalase. At the end of the incubation, cells were washed three times with EBSS. $1 \mathrm{ml}$ of $10 \%$ cold TCA was added to the cell pellet together with $10 \mu \mathrm{l}$ of $20 \% \mathrm{BSA}$ as carrier. The mixture was incubated at $4^{\circ} \mathrm{C}$ overnight before centrifugation at $15,000 \mathrm{rpm}$ for $15 \mathrm{~min}$. The supernatant was collected and counted. The precipitate was washed once with an additional $1 \mathrm{ml}$ cold TCA and the pellet was solubilized with $0.5 \mathrm{ml}$ of $1 \%$ SDS and counted.
}

prevent extracellular methionine oxidation suggested that intracellular events were responsible.

The synthesis of phosphatidylcholine from phosphatidylethanolamine by successive methylations (16), and the incorporation of methyl groups into neutral lipids, representing a step required for the biosynthesis of ubiquinone (18), are amongst the methylation reactions employing S-adenosyl-methionine as the active methyl donor. The final products of these two reactions have different roles in the biology of the cell. Nevertheless, both methylation reactions were decreased in a similar manner by treatment of cells with the chemoattractant, FMLP, or other nonchemotactic activators of the respiratory burst, which suggests that this phenomenon was related to a common event. The decrease in methyl group incorporation into lipids induced by FMLP and TPA was apparent over the same concentration range that stimulated $\mathrm{O}_{2}^{-}$production by monocytes. Furthermore, no change in methyl group incorporation was observed in TPA-treated lymphocytes, which do not undergo an oxidative burst. These data suggest an inverse relationship between activation of the oxidative burst and methyl group incorporation into lipids in stimulated monocytes, and allowed us to hypothesize that events related to the activation of the respiratory burst might be responsible for the simultaneous change we observed in the two different methylation pathways we examined.

We found that stimulated monocytes oxidize methionine to methionine sulfoxide in the medium, as has been described for human neutrophils (27). This event is related to activation of the respiratory burst, although the precise nature of the oxidizing agent is not known $(27,19)$. Because methionine sulfoxide is less efficient than methionine in entering cells and may not act as a methyl-donor even when present inside the cell, the 
effect of stimuli of the oxidative burst on the incorporation of methyl group into lipids might be primarily related to extracellular oxidation of methionine. If this were the case, the observed decrease in methyl group incorporation we found would not necessarily reflect an actual change in the extent of methylation, since a resynthetic pathway for methionine in mammalian cells exists (28). However, when accumulation of methionine sulfoxide was eliminated by replacement with fresh medium, or when extracellular oxidation of methionine was prevented by nonpenetrating agents, the decreased level of lipid methylation in TPA-treated monocytes was not similarly corrected. Under these conditions, an increase of radioactivity from labeled methionine in the TCA-soluble pool together with a decreased radioactivity in the TCA-precipitable pool were found, suggesting an impaired methionine utilization. These observations raised the possibility that stimulation of the respiratory burst might lead to oxidation of methionine to methionine sulfoxide after its entrance into the cells, and might account for the decreased methylation observed in our system. This is consistent with the detection of intracellular methionine sulfoxide in stimulated human neutrophils (27).

A pivotal role for methionine in modulating the inhibitory effect of stimuli of the oxidative burst on lipid methylation was suggested by the dependency of the effect on the concentration of methyl-donor. Since the intracellular and extracellular pools are readily equilibrated (29), increasing the concentration of methionine in the medium would result in a limitation of the inhibitory effect, possibly by supplying additional amounts of substrate. In a physiologic context, the human plasma concentration of methionine, under usual conditions, may vary from 10 to $40 \mu \mathrm{M}$, with fluctuation related to dietary intake (30). This is within the range where the effect of potent stimulation of the respiratory burst on lipid methylation could be manifest.

Although we favor the hypothesis that reduced availability of intracellular methyl-donor is the most likely explanation for the observations described, alternative interpretations of the reduced level of methylation observed may be considered. Amongst these interpretations are: decreased activity of methyltransferase enzymes, as has been reported for the phospholipid methyltransferase activity of zymosan-stimulated neutrophils (31), and enhanced catabolism of the methylated products as a result of treatment with the agents employed in this study. The demonstrated ability to reverse the reduction in methyl group incorporation into both lipid fractions by increasing the concentration of methionine in the medium make a decreased enzymatic activity unlikely. Furthermore, phospholipid methyltransferase activity of TPA-treated cells was not different from controls in a cell-free assay ${ }^{3}$. Neither was enhanced catabolism of methylated products likely to be responsible for the observed effect. Although activation of phospholipase $A_{2}$ has been described to account for reducing the recovery of methyl-labeled

3. Bougnoux, P., E. Bonvini, H. C. Stevenson, and T. Hoffman. Manuscript in preparation. phospholipids in stimulated rabbit neutrophils (17), this observation was not confirmed in guinea pig macrophages (15). The decay of labeled phospholipids was not consistently enhanced by TPA-treatment of monocytes and its magnitude could not uniquely account for the decrease we observed in this lipid fraction $^{3}$. Furthermore, the decrease in methyl group incorporation into phospholipids paralleled that of the neutral lipid compound, ubiquinone; its slow decay has been shown not to be affected by TPA treatment (18).

Inhibition of phospholipid methylation by chemotactic factors has been described in guinea pig macrophages and was correlated with the potency of the agents tested as chemoattractants (15). Phospholipid methylation was deemed to be specifically affected by the chemotactic agents, since a different stimulus, phagocytosis of opsonized sheep erythrocytes, resulted in no change and a second methylation reaction, protein carboxyO-methylation, was unaffected by the chemotactic factors employed. The data obtained here employing nonchemotactic stimuli of the oxidative burst failed to support the specificity observed in guinea pig macrophages. Although phagocytosis usually is associated with an activated respiratory burst, differences among species and efficiency of the stimulus employed might account for the discrepancy. The effect we observed on neutral lipid methylation in human monocytes argues against the unique involvement of phospholipid methylation after chemoattractant exposure; instead, the mechanism reported here is also likely to affect other methionine-dependent reactions. For example, we observed a decreased amount of radioactivity from labeled methionine recovered in the TCA-precipitable material of stimulated monocytes, which argues that there are possible effects on other metabolic pathways, including protein synthesis. This is in agreement with a report showing that methionine sulfoxide is not incorporated into protein in a cell-free system (32).

The relationship we observed in our system between the activation of the oxidative burst and the inhibition of lipid methylation might contribute to the understanding of biochemical phenomena associated with the expression of cell functions. Conversely, a comprehension of actions of agents that can trigger the activation of the respiratory burst in responsive cells may be approached in terms of oxidation of susceptible substrates, such as methionine.

\section{Acknowledgments}

We are grateful to Dr. Ronald B. Herberman and Dr. Joost J. Oppenheim for reviewing the manuscript and to Dr. Edward Leonard, Dr. Luigi Varesio, and Dr. Norman Salem, Jr. for helpful discussion. We are indebted to Dr. Theresa Gerard for providing elutriator-purified monocytes during the completion of this study.

\section{References}

1. Cantoni, G. L. 1975. Biological methylation: selected aspects. Annu. Rev. Biochem. 44:435-451. 
2. Paik, W. K., and S. Kim. 1975. Protein methylation: chemical, enzymological, and biological significance. Adv. Enzymol. Relat. Areas Mol. Biol. 42:227-286.

3. Pick, E., and D. Mizel. 1982. Role of transmethylation in the elicitation of an oxidative burst in macrophages. Cell. Immunol. 72:277285.

4. Pike, M. C., and R. Snyderman. 1982. Transmethylation reactions regulate affinity and functional activity of chemotactic factor receptors on macrophages. Cell. 28:107-114.

5. Leonard, E. J., A. Skeel, P. K. Chiang, and G. L. Cantoni. 1978. The action of the adenosylhomocysteine inhibitor, 3-deazaadenosine, on phagocytic function of mouse macrophages and human monocytes. Biochem. Biophys. Res. Commun. 84:102-109.

6. Pike, M. C., N. M. Kredick, and R. Snyderman. 1978. Requirement of $S$-adenosyl- $L$-methionine-mediated methylation for human monocyte chemotaxis. Proc. Natl. Acad. Sci. USA. 75:3928-3932.

7. Snyderman, R., M. C. Pike, and N. M. Kredich. 1980. Role of transmethylation reactions in cellular motility and phagocytosis. $\mathrm{Mol}$. Immunol. 17:209-218.

8. Pike, M. C., and R. Snyderman. 1981. Transmethylation reactions are required for the initial morphologic and biochemical response of human monocytes to chemoattractants. J. Immunol. 127:1444-1449.

9. Aksamit, R. R., W. Falk, and G. L. Cantoni. 1982. Inhibition of chemotaxis by $S$-3-deazaadenosylhomocysteine in a mouse macrophage cell line. J. Biol. Chem. 257:621-625.

10. Adams, D. O., M. C. Pike, and R. Snyderman. 1981. The role of transmethylation reactions in regulating the binding of BCG-activated murine macrophages to neoplastic target cells. J. Immunol. 127:225230.

11. Kort, E. N., M. F. Goy, S. H. Larsen, and J. Adler. 1975. Methylation of a membrane protein involved in bacterial chemotaxis. Proc. Natl. Acad. Sci. USA. 72:3939-3943.

12. Springer, W. R., and D. E. Koshland, Jr. 1977. Identification of a protein methyltransferase as the gene product in the bacterial sensing system. Proc. Natl. Acad. Sci. USA. 74:533-537.

13. Springer, W. R., M. F. Goy, and J. Adler. 1977. Sensory transduction in Escherichia coli: two complementary pathways of information processing that involve methylated proteins. Proc. Natl. Acad. Sci. USA. 74:3312-3316.

14. O’Dea, R. F., O. H. Viveros, J. Axelrod, S. Aswanikumar, E. Schiffman, and B. A. Corcoran. 1978. Rapid stimulation of protein carboxymethylation in leukocytes by a chemotactic peptide. Nature (Lond.). 272:462-464.

15. Pike, M. C., N. M. Kredich, and R. Snyderman. 1979. Phospholipid methylation in macrophages is inhibited by chemotactic factors. Proc. Natl. Acad. Sci. USA. 76:2922-2926.

16. Hirata, F., and J. Axelrod. 1980. Phospholipid methylation and biological signal transmission. Science (Wash. DC). 209:1082-1090.

17. Hirata, F., B. A. Corcoran, K. Venkatasubramanian, E. Schiffman, and J. Axelrod. 1979. Chemoattractants stimulate degradation of methylated phospholipids and release of arachidonic acid in rabbit leukocytes. Proc. Natl. Acad. Sci. USA. 76:2640-2643.
18. Bougnoux, P., E. Bonvini, H. C. Stevenson, S. Markey, M. Zatz, and T. Hoffman. 1983. Identification of ubiquinone-50 as the major methylated non-polar lipid in human monocytes. Regulation of its biosynthesis via methionine-dependent pathways and relationship to superoxide production. J. Biol. Chem. 258:4339-4344.

19. Tsan, M. F. 1982. Myeloperoxidase-mediated oxidation of methionine and amino acid decarboxylation. Infect. Immun. 36:136-141.

20. Stevenson, H. C., and A. S. Fauci. 1981. Countercurrent centrifugation elutriation. In Manual of Macrophage Methodology. H. B. Herscowitz, H. T. Holden, J. A. Bellanti, and A. Ghaffar, editors. Marcel Dekker, New York. 75.

21. Li, C. Y., K. W. Lam, and L. T. Yam. 1973. Esterases in human leukocytes. J. Histochem. Cytochem. 21:1-12.

22. Bligh, E. G., and W. J. Dyer. 1959. A rapid method of total lipid extraction and purification. Can. J. Biochem. Physiol. 37:911-917.

23. Snyderman, R., L. C. Altman, M. S. Hausman, and S. E. Mergenhagen. 1972. Human mononuclear leukocyte chemotaxis: a quantitative assay for mediators of humoral and cellular chemotactic factors. J. Immunol. 108:857-860.

24. Zigmond, S. H., and J. G. Hirsch. 1973. Leukocyte locomotion and chemotaxis. New methods for evaluation, and demonstration of a cell derived chemotactic factor. J. Exp. Med. 137:387-410.

25. Pick, E., and D. Mizel. 1981. Rapid microassay for measurement of superoxide and hydrogen peroxide production by macrophages in culture using an automatic enzyme immunoassay reader. J. Immunol. Methods. 46:211-226.

26. Baird, W. M., L. Diamond, T. W. Borun, and S. Shulman. 1979. Analysis of metabolism of carcinogenic polycyclic hydrocarbons by position-sensing proportional counting of thin-layer chromatograms. Anal. Biochem. 99:165-169.

27. Tsan, M. F., and J. W. Chen. 1980. Oxidation of methionine by human polymorphonuclear leukocytes. J. Clin. Invest. 65:1041-1050.

28. Finkelstein, J. D. 1979. Regulation of methionine metabolism in mammals. In Transmethylation. E. Usdin, R. T. Borchardt, and C. R. Creveling, editors. Elsevier/North-Holland, New York. 49-58.

29. Moore, J. P., G. A. Smith, T. R. Hesketh, and J. C. Metcalfe. 1982. Early increases of phospholipid methylation are not necessary for the mitogenic stimulation of lymphocytes. J. Biol. Chem. 257:81838189.

30. Frenstrom, J. D., R. J. Wurtman, B. Hammarstrom-Wiklund, W. R. Rand, H. N. Munro, and C. S. Davidson. 1979. Diurnal variation in plasma concentrations of tryptophan, tyrosine and other neutral amino acids: effect of dietary protein intake. Am. J. Clin. Nutr. 32:1912-1922.

31. Gil, M. G., F. Alonso, M. Sánchez-Crespo, and J. M. Mato. 1981. Inhibition of phospholipid methyltransferase during zymosaninduced secretion of platelet-activating factor in human polymorphonuclear leukocytes. Biochem. Biophys. Res. Commun. 101:740-748.

32. Lemoine, F., J. P. Walker, and R. van Rapenbusch. 1968. Studies on methionyl transfer RNA synthetase. I. Purification and some properties of methionyl transfer RNA synthetase from Escherichia coli K-12. Eur. J. Biochem. 4:213-221. 